\title{
Frailty, prefrailty and employment outcomes in Health and Employment After Fifty (HEAF) Study
}

\author{
Keith T Palmer, ${ }^{1,2}$ Stefania D'Angelo, ${ }^{1,2}$ E Clare Harris, ${ }^{1,2}$ Cathy Linaker, ${ }^{1,2}$ \\ Catharine R Gale, ${ }^{1,3}$ Maria Evandrou, ${ }^{4}$ Holly Syddall, ${ }^{1}$ Tjeerd van Staa, 5,6 \\ Cyrus Cooper, ${ }^{1,2}$ Avan Aihie Sayer, ${ }^{1,7,8,9,10}$ David Coggon, ${ }^{1,2}$ Karen Walker-Bone ${ }^{1,2}$
}

\begin{abstract}
- Additional material is published online only. To view please visit the journal online (http://dx.doi.org/10.1136/ oemed-2016-104103).
\end{abstract}

For numbered affiliations see end of article.

\section{Correspondence to} Professor Keith T Palmer, Medical Research Council Lifecourse Epidemiology Unit, University of Southampton, Southampton General Hospital, Southampton S016 6YD, UK; ktp@mrc.soton.ac.uk

Received 21 September 2016 Revised 7 December 2016 Accepted 19 December 2016 Published Online First 6 January 2017

\section{Linked}

- http://dx.doi.org/10.1136/ oemed-2017-104291

\section{CrossMark}

To cite: Palmer KT,

D'Angelo S, Harris EC,

et al. Occup Environ Med

2017:74:476-482.

\begin{abstract}
Objectives Demographic changes are requiring people

to work longer. No previous studies, however, have focused on whether the 'frailty' phenotype (which predicts adverse events in the elderly) is associated with employment difficulties. To provide information, we assessed associations in the Health and Employment After Fifty Study, a population-based cohort of 50-65year olds.
\end{abstract}

Methods Subjects, who were recruited from 24 English general practices, completed a baseline questionnaire on 'prefrailty' and 'frailty' (adapted Fried criteria) and several work outcomes, including health-related job loss (HRJL), prolonged sickness absence ( $>20$ days vs less, past 12 months), having to cut down substantially at work and difficulty coping with work's demands. Associations were assessed using logistic regression and population attributable fractions (PAFs) were calculated. Results In all, 3.9\% of 8095 respondents were classed as 'frail' and $31.6 \%$ as 'prefrail'. Three-quarters of the former were not in work, while $60 \%$ had left their last job on health grounds (OR for HRJL vs non-frail subjects, 30.0 (95\% Cl 23.0 to 39.2)). Among those in work, ORs for prolonged sickness absence, cutting down substantially at work and struggling with work's physical demands ranged from 10.7 to 17.2. The PAF for HRJL when any frailty marker was present was $51.8 \%$ and that for prolonged sickness absence was $32.5 \%$. Associations were strongest with slow reported walking speed. Several associations were stronger in manual workers than in managers.

Conclusions Fried frailty symptoms are not uncommon in mid-life and are strongly linked with economically important adverse employment outcomes. Frailty could represent an important target for prevention.

By 2060, 30\% of the European population will be aged over 65 years. Increasingly, therefore, western governments have been implementing policies to encourage people to remain in work longer, to support themselves and others. ${ }^{1}$ However, for people with chronic diseases, extended working life may be infeasible, particularly if their jobs require substantial physical effort. Strategies may be needed to identify workers at particular risk of healthrelated job loss (HRJL), when older, and to assist them-for example, through interventions to promote their fitness in middle and later life.

In elderly care medicine, a phenotype of physical frailty has been found to be a useful target for

\section{What this paper adds}

- In elderly care medicine, a phenotype of physical 'frailty' has been found to predict many adverse health outcomes and has proved a target for intervention.

- The potential impact of the phenotype on employment has not been studied previously, however.

- Using a symptom checklist adapted from previous research, we have found that 'frailty' symptoms are not uncommon in people aged 50-65 years in the English general population and are very strongly associated cross-sectionally with worklessness, health-related job loss, sickness absence and not coping at work.

- Our findings need to be corroborated longitudinally, and the physical function and clinical features of those with multiple symptoms characterised, as a possible prelude to developing instruments to screen for frailty in employment.

interventions. $^{2} 3$ 'Frailty' thus defined is characterised by age-related declines in functional reserves across a range of physiological systems. Frail elderly people are at heightened risk of many adverse outcomes including dependency, institutionalisation, falls, fractures, hospitalisation and mortality, and they have higher rates of comorbidity and disability. ${ }^{2-7}$ Clinical trials have suggested that the frailty status may be reversible and that some of these events may thereby be avoidable. ${ }^{8-10}$

While frailty is generally regarded as a problem of old age, the symptoms by which the phenotype is identified can also occur in younger people. However, 'frailty' has seldom been studied in people of working age ${ }^{11}$ and never, to the best of our knowledge, investigated in relation to work incapacity. Conceivably, symptoms of frailty could be useful markers for employment difficulties in late middle age, in which case, by analogy with advances in elderly care, there could be scope to intervene to prevent HRJL and premature retirement.

To provide initial information in this area, we used baseline data on people aged 50-65 years who 
were enrolled into the Health and Employment After Fifty (HEAF) Study ${ }^{12}$ to assess the prevalence and interrelationship of symptoms of physical frailty, and to explore their associations with various adverse employment outcomes.

In previous research, 'frailty' has been defined in more than 20 separate ways, ${ }^{13}$ among which the criteria of Fried $e t a l^{2}$ are widely used. These comprise five items of unintentional weight loss, self-reported exhaustion, slow walking speed, low physical activity levels and weakness of grip. We assessed: (1) whether 'frailty', defined by these criteria, was associated with adverse employment outcomes (worklessness, HRJL, prolonged sick leave, having to cut down a lot and failing to cope at work); (2) how much it contributed to the population burden of such outcomes; (3) whether findings varied by the nature of a person's occupation and (4) whether different elements of the case definition were more importantly associated with work difficulties than others.

\section{METHODS}

The HEAF cohort is nested within the Clinical Practice Research Datalink (CPRD), a British primary care research database. Details of recruitment and data collection have been published elsewhere. ${ }^{12}$ In brief, in 2013-2014, a sampling frame was drawn up of patients born between 1948 and 1962 (target ages 50-64 years) who were registered with 24 English general practices contributing data to the CPRD. Questionnaires were mailed to 39359 people $(97.5 \%$ of those identified, and excluding those who had illness or recent bereavement, or had deregistered during the interval between sampling and mailing). In all, 8134 subjects returned a valid questionnaire (some of whom were aged 65 by the time they completed the form).

Relevant to this analysis were a panel of questions about physical function, health and employment outcomes. To assess frailty we adapted the Fried criteria using questionnaire items on:

1. Weight loss: in the past 12 months, weight loss of more than $10 \mathrm{lbs}(4.5 \mathrm{~kg})$ unintentionally, that is, without dieting and exercise (yes vs no);

2. Exhaustion: in the past 7 days, everything being an effort or not being able to 'get going' (either or both, for most or all of the time);

3. Slowness: normal walking speed described as 'unable to walk' or 'very slow';

4. Weakness of grip strength: moderate or severe difficulty in opening jars that had never previously been opened;

5. Inactivity: in an average week, and outside any paid jobs, doing no physical activity sufficient to make the respondent hot or sweaty.

Questions 1 and 2 were those used by Fried $e t a l .^{2}$ Questions 3-5 approximated the corresponding criteria, which were originally based on the bottom fifths of measured walking speed, measured grip strength and self-reported weekly physical activity. According to the Fried case definition, an elderly person meeting three or more of the five criteria would be counted as 'frail', while a person meeting one or two of the criteria would be classed as 'prefrail'. As in Fried's original report, we excluded subjects with three or more missing responses to the frailty items (39 subjects), leaving 8095 people in the analysis.

Employment-related questions in the HEAF baseline questionnaire included current employment status and, if not working, whether the previous job had been surrendered for a health reason (analysed as not in work vs in work and left for a health reason vs not); occupation or last held occupation (used to classify subjects' jobs according to the Standard Occupational
Classification 2010 (SOC 2010) ${ }^{14}$ as higher managerial, intermediate occupation or routine/manual occupation); and for those in work: total sickness absence in the past 12 months $(0$, $<5,5-20$, or $>20$ days, analysed as 'any absence vs none' and ' $>20$ vs $\leq 20$ days of absence'); needing to cut down at work in the past 12 months because of health (not at all, a little or a lot, analysed as 'any vs none' and 'a lot vs not'); current coping with work's physical and mental demands (with some/great difficulty vs easily); expecting to be physically and mentally able still to carry out the same kind of work in 2 years' time (no/not sure vs yes); perceived job security (rather/very insecure vs secure/very secure) and ever lying awake at night, worrying or angry about work (often vs sometimes/rarely/never). These items (other than social class) were assessed as outcomes in relation to markers of frailty.

Also, information was collected on several potential confounders of associations, namely: low well-being, according to the 14-item Warwick-Edinburgh Mental Well-being Scale (WEMWBS) ${ }^{15}$ (bottom fifth of scores vs the rest); and pain for a month or longer in the past 12 months which affected back or neck, arms or shoulders, or legs and which made it difficult or impossible to get washed or dressed or do household chores ('persistent' pain at $0,1,2-3$ sites, analysed as pain at least at one site vs no pain).

Data were described using basic summary statistics and crosstabulations were used to assess their overlap and association with one another. Associations between components of the Fried frailty criteria and employment variables were assessed by logistic regression and summarised by ORs with 95\% CIs. Analyses were repeated separately for strata of social class defined from current or last held occupation. For measures of work loss, we also estimated the population attributable fractions (PAFs) associated with the presence of different numbers of Fried symptoms. A PAF represents the proportion of cases in a population that would be eliminated if all people had the same risk as those in the reference category. Finally, in a sensitivity analysis, we assessed the further impact of adjustment for low well-being and persistent musculoskeletal pain, these being other markers of ill health that might confound associations of frailty with the work outcomes. All analyses were conducted for men and women combined with adjustment for age (as a continuous measure) and gender and using Stata statistical software, release 14 .

\section{RESULTS}

The characteristics of the study participants are summarised in table 1: $46 \%$ were male participants, the average age was 58.7 years (SD 4.4 years, range 50 to 65 ), and $27.3 \%$ of men and $36.4 \%$ of women reported that they were no longer working. Among those not in work, $37.6 \%$ of men and $32.6 \%$ of women reported that they had left their last employment wholly or partly because of a health problem. Musculoskeletal disorders and mental illness were the most commonly cited health reasons for stopping work. In addition, many of the 2682 men and 2804 women who were still in work reported reduced participation in, or difficulties with, their employment. For example, $6.2 \%$ of the men and $7.2 \%$ of the women had taken 20 or more days sick leave in the past 12 months, and $28.9 \%$ of the men and $30.2 \%$ of the women reported some or great difficulty in coping with work's physical demands. About one in five reported their job to be insecure or very insecure.

Table 2 shows the prevalence of symptoms used to define frailty, overall and by gender. By our adapted case definition, $313(3.9 \%)$ of the 8095 eligible respondents were classified as 
Table 1 Characteristics of the participants

\begin{tabular}{|c|c|c|c|c|}
\hline & \multicolumn{2}{|l|}{ Men } & \multicolumn{2}{|c|}{ Women } \\
\hline & $\mathrm{N}$ & Per cent* & & Per cent* \\
\hline Whole sample & 3689 & & 4406 & \\
\hline Age, mean (SD) & & $58.7(4.4)$ & & $58.6(4.4)$ \\
\hline \multicolumn{5}{|l|}{ Social class } \\
\hline Higher managerial & 1543 & 42.5 & 1699 & 39.1 \\
\hline Intermediate occupations & 795 & 21.9 & 1437 & 33.0 \\
\hline Routine and manual occupations & 1291 & 35.6 & 1215 & 27.9 \\
\hline \multicolumn{5}{|l|}{ Employment status } \\
\hline In work & 2682 & 72.7 & 2804 & 63.6 \\
\hline Not in work & 1007 & 27.3 & 1602 & 36.4 \\
\hline Retired (not for health reason) & 517 & 14.0 & 927 & 21.0 \\
\hline Unemployed (not for health reason) & 111 & 3.0 & 152 & 3.4 \\
\hline $\begin{array}{l}\text { Left for health reason (unemployed } \\
\text { or retired) }\end{array}$ & 379 & 10.3 & 523 & 11.9 \\
\hline \multicolumn{5}{|l|}{ Current workers } \\
\hline Any sick leave, past 12 months & 1003 & 37.8 & 1346 & 48.4 \\
\hline$\geq 20$ days sick leave, past 12 months & 163 & 6.2 & 200 & 7.2 \\
\hline $\begin{array}{l}\text { Cutting down at work to any extent, } \\
\text { past } 12 \text { months }\end{array}$ & 669 & 25.1 & 770 & 27.6 \\
\hline $\begin{array}{l}\text { Cutting down at work a lot, past } \\
12 \text { months }\end{array}$ & 142 & 5.3 & 170 & 6.1 \\
\hline $\begin{array}{l}\text { Not coping with work's physical } \\
\text { demands }\end{array}$ & 763 & 28.9 & 837 & 30.2 \\
\hline $\begin{array}{l}\text { Not coping with work's mental } \\
\text { demands }\end{array}$ & 779 & 29.5 & 937 & 33.8 \\
\hline $\begin{array}{l}\text { Expecting not to be able to cope at } \\
\text { work in } 2 \text { years' time }\end{array}$ & 551 & 21.0 & 791 & 28.5 \\
\hline $\begin{array}{l}\text { Often lying awake worrying about } \\
\text { work }\end{array}$ & 291 & 11.0 & 412 & 14.8 \\
\hline Job insecure/very insecure & 532 & 20.2 & 509 & 18.4 \\
\hline
\end{tabular}

${ }^{*}$ For current workers, percentages relate to those in work.

'frail' (3-5 symptoms present) and, within this subgroup, low physical activity, weakness of grip and slow walking speed were reported by $77 \%, 87 \%$ and $82 \%$ of subjects, respectively. Some $2560(31.6 \%)$ subjects were counted as 'prefrail' (1 or 2 symptoms present) by our adapted Fried criteria. Women were more likely than men to report symptoms, individually and in combination, with $4.9 \%$ of women but $2.7 \%$ of men reporting $\geq 3$ symptoms.

Certain symptoms associated with one another particularly strongly, notably slow walking speed with weak grip (OR 11.9) and exhaustion (OR 10.5) and slow walking speed with low physical activity (OR 6.1) and weak grip with exhaustion (OR 6.1). In contrast, associations of unintentional weight loss and low physical activity with other frailty indicators tended to be weaker (see online supplementary table S1).

Table 3 presents the associations between number of frailty symptoms and work outcomes, and provides estimates of the relevant PAFs. Relationships with employment status, including whether the previous job was surrendered for a health reason, were explored in all subjects, whereas those with sickness absence, needing to cut down a lot at work and various perceptions about work (eg, self-reported coping, future expectations, worry over work and job dissatisfaction) were restricted to the 5486 respondents in paid work.

Three-quarters of those classed as 'frail' were no longer working, and 60\% reported leaving their last job for a health reason; corresponding proportions among the 'non-frail' (those with no Fried symptoms) were $28 \%$ and $5 \%$, respectively ( $\mathrm{p} \leq 0.001$ for differences). The odds of not being in paid work were elevated 10.5 -fold in 'frail' versus 'non-frail' subjects, and the OR for HRJL was even higher (OR 30.0, 95\% CI 23.0 to 39.2). Adverse work outcomes were also more frequent in those classed as 'prefrail', although associations were weaker (ORs vs 'non-frail', 1.4 and 3.7, respectively).

Among the 5486 people in paid work, 78 (1.4\%) met our criteria for 'frailty' while $1654(30.2 \%)$ were classed as 'prefrail'. Relative to those with no Fried symptoms, the former group had much higher odds of prolonged sickness absence in the past year (OR 10.7, 95\% CI 6.5 to 17.7), needing to cut down a lot on work in the past 12 months (OR 17.2, 95\% CI 10.5 to 28.4), difficulty coping with work's physical demands (OR $14.8,95 \%$ CI 8.2 to 26.6 ) and being unsure whether they would be able to cope with work in 2 years' time (OR 14.5, 95\% CI 8.2 to 25.4). Even for 'prefrailty', many ORs were of the order of $2-3(\mathrm{p}<0.001)$.

A total of 873 'prefrail' subjects were classed as such solely because they did not report physical exercise or sports in an average week sufficient to make them hot or sweaty. In case this criterion lacked specificity, we repeated the analysis for table 3 for an alternative case definition of prefrailty requiring the presence of two symptoms. In this sensitivity analysis, ORs for adverse work outcomes were strengthened, although below those for frailty (eg, the OR for HRJL was 9.6 (95\% CI 7.612.0 , vs 3.7) and that for sick leave $>20$ days in the past 12 months was 6.2 (95\% CI 4.5 to 8.6 vs 2.5$)$ ).

Assuming causal relationships, PAFs for HRJL were 20.3\% for the presence of $\geq 3$ Fried symptoms and $34.9 \%$ for $1-2$ symptoms (table 3), while among those in paid work, $6.5 \%$ and

Table 2 Prevalence of Fried symptoms

\begin{tabular}{|c|c|c|c|c|c|}
\hline Symptoms & $\begin{array}{l}\text { All } \\
\mathrm{N}(\%)\end{array}$ & $\begin{array}{l}\text { Men } \\
\mathrm{N}(\%)\end{array}$ & $\begin{array}{l}\text { Women } \\
\mathrm{N}(\%)\end{array}$ & $\begin{array}{l}\text { 'Prefrail'* individuals } \\
\text { N (\%) }\end{array}$ & $\begin{array}{l}\text { 'Frail'* individuals } \\
\mathrm{N}(\%)\end{array}$ \\
\hline Low physical activity & $1355(18.8)$ & $589(17.5)$ & $766(20.0)$ & $1161(51.5)$ & $194(77.0)$ \\
\hline Weakness of grip & $1001(12.5)$ & $192(5.3)$ & 809 (18.6) & $730(28.8)$ & $271(87.1)$ \\
\hline Unintentional weight loss & $753(9.4)$ & $327(8.9)$ & $426(9.7)$ & $605(23.7)$ & $148(47.7)$ \\
\hline Slow walking speed & $536(6.6)$ & $233(6.3)$ & $303(6.9)$ & $278(10.9)$ & $258(82.4)$ \\
\hline Exhaustion & $526(6.5)$ & $194(5.3)$ & $332(7.6)$ & $333(13.1)$ & $193(61.7)$ \\
\hline \multicolumn{6}{|l|}{ Number of frailty symptoms: } \\
\hline None & $5222(64.5)$ & $2597(70.4)$ & $2625(59.6)$ & & \\
\hline 1-2 symptoms ('prefrail') & $2560(31.6)$ & $993(26.9)$ & $1567(35.5)$ & & \\
\hline$\geq 3$ symptoms ('frail') & $313(3.9)$ & $99(2.7)$ & $214(4.9)$ & & \\
\hline
\end{tabular}

*'Prefrail', 1-2 symptoms; 'frail', 3-5 symptoms. 
Table 3 Associations between number of frailty symptoms and employment outcomes and perceptions

\begin{tabular}{|c|c|c|c|c|c|c|c|}
\hline \multirow[b]{3}{*}{ Outcomes } & \multirow{3}{*}{$\begin{array}{l}\mathrm{N}(\%) \text { with work outcome } \\
\text { among participants with no } \\
\text { frailty symptoms }\end{array}$} & \multicolumn{6}{|l|}{ Risk factor } \\
\hline & & \multicolumn{3}{|c|}{ 'Prefrail' (1-2 vs 0 symptoms) } & \multicolumn{3}{|c|}{ 'Frail' (3-5 vs 0 symptoms) } \\
\hline & & $\begin{array}{l}\text { N (\%) } \\
\text { Positive }\end{array}$ & OR $(95 \% \mathrm{Cl})$ & PAF & $\begin{array}{l}\mathrm{N}(\%) \\
\text { Positive }\end{array}$ & OR $(95 \% \mathrm{Cl})$ & PAF \\
\hline \multicolumn{8}{|l|}{ Entire sample $(\mathrm{n}=8095)$} \\
\hline Not in work vs in work & $1468(28.1)$ & $906(35.4)$ & $1.4(1.2,1.6)$ & $9.7 \%$ & $235(75.1)$ & $10.5(7.9,14.1)$ & $8.2 \%$ \\
\hline $\begin{array}{l}\text { Left for a health reason vs not } \\
\text { Those in work }(n=5486)\end{array}$ & \multicolumn{6}{|c|}{ Those in work $(\mathrm{n}=5486)$} & $20.3 \%$ \\
\hline \multicolumn{8}{|c|}{ Sick leave, days past 12 months ( $\max n=5457$ ): } \\
\hline Any vs none & $1468(39.4)$ & $827(50.8)$ & $1.5(1.4,1.7)$ & $12.2 \%$ & $54(70.1)$ & $3.4(2.1,5.5)$ & $1.6 \%$ \\
\hline$>20$ days vs $\leq 20$ days & $168(4.5)$ & $169(10.4)$ & $2.5(2.0,3.1)$ & $27.6 \%$ & $26(33.8)$ & $10.7(6.5,17.7)$ & $6.5 \%$ \\
\hline \multicolumn{8}{|l|}{ Cut down on work, past 12 months: } \\
\hline Any vs none & $787(21.1)$ & $596(36.5)$ & $2.2(1.9,2.4)$ & $22.2 \%$ & $56(72.7)$ & $10.0(6.0,16.6)$ & $3.5 \%$ \\
\hline A lot vs not a lot (none/a little) & $128(3.4)$ & $155(9.5)$ & $3.0(2.3,3.8)$ & $33.0 \%$ & $29(37.7)$ & $17.2(10.5,28.4)$ & $8.8 \%$ \\
\hline \multicolumn{8}{|c|}{ Coping with work's physical demands (vs easily): } \\
\hline With some/great difficulty & $848(22.9)$ & $691(42.0)$ & $2.4(2.2,2.8)$ & $25.5 \%$ & $61(81.3)$ & $14.8(8.2,26.6)$ & $3.6 \%$ \\
\hline \multicolumn{8}{|c|}{ Coping with work's mental demands (vs easily): } \\
\hline With some/great difficulty & $1029(27.9)$ & $640(38.9)$ & $1.7(1.5,1.9)$ & $14.8 \%$ & $47(62.7)$ & $4.5(2.8,7.3)$ & $2.1 \%$ \\
\hline \multicolumn{8}{|c|}{ Expecting to be able to cope in 2 years' time (vs yes): } \\
\hline No/not sure & $717(19.4)$ & $566(34.6)$ & $2.1(1.9,2.4)$ & $22.3 \%$ & $59(78.7)$ & $14.5(8.2,25.4)$ & $4.1 \%$ \\
\hline \multicolumn{8}{|c|}{ Lying awake at night worrying about work (vs sometimes/rarely/never): } \\
\hline Often & $375(10.1)$ & $300(18.2)$ & $2.0(1.7,2.3)$ & $20.8 \%$ & $28(36.8)$ & $1.2(1.0,1.4)$ & $3.2 \%$ \\
\hline \multicolumn{8}{|l|}{ Job security (vs secure/very secure): } \\
\hline Insecure/very insecure & $671(18.2)$ & $341(20.8)$ & $5.1(3.2,8.3)$ & $5.6 \%$ & $29(38.7)$ & $3.0(1.9,4.8)$ & $1.9 \%$ \\
\hline
\end{tabular}

$27.6 \%$ of prolonged sickness absence would be attributable to these factors on the same basis. PAFs for other employment outcomes are recorded in table 3.

Further adjustment for low well-being and persistent musculoskeletal pain, in addition to age and gender, reduced these risk estimates somewhat. However, those for 'frailty' all remained significantly and in most cases substantially elevated, and the OR for HRJL, was still greater than 14 (see online supplementary table S2).

To explore whether the associations presented in table 3 differed by socioeconomic status, the analyses were repeated within strata of social class determined from the current or last held job (higher managerial, intermediate or manual/routine). Associations with not being in work, taking any sick leave and not coping with work's demands were about 2-3 times greater among those from the lowest versus the highest social class, but no differential was apparent for HRJL, prolonged sick leave, cutting down at work or perceived job insecurity (table 4). However, 'frailty' was strongly associated with these adverse outcomes, even in higher managerial workers (eg, OR for HRJL, 29.4 (95\% CI 17.5 to 49.3 )).

Finally, table 5 considers the same employment outcomes but with symptoms of 'frailty' treated as individual risk factors. Almost all outcomes were more strongly associated with slow walking speed than with the other symptoms, resulting, for example, in ORs of 9.6 to 14.8 for HRJL, cutting down a lot at work and difficulty coping with work's physical demands, vs 1.9 to 7.4 for the remaining symptoms. Strong, albeit weaker, associations were found for poor grip strength and exhaustion, and the latter had the strongest relationship to not coping mentally at work. In contrast, unintentional weight loss and our index of low physical activity were only weakly associated with the employment outcomes.

\section{DISCUSSION}

In this analysis of over 8000 people aged 50-65 years from English general practices, we assessed frailty using questionnaire items adapted from the Fried criteria. Almost one in three subjects was 'prefrail' by our definition and 3.9\% were 'frail'. Our case definition for frailty was associated strongly with being out of work, HRJL, prolonged sickness absence, having to cut down a lot on work activities, self-reports of not coping with work's demands and negative perceptions about work, including job insecurity and worry over work with loss of sleep. PAFs were relatively high and, for the presence of any of the frailty symptoms, exceeded 50\% for HRJL and reached almost one-third for prolonged sickness absence.

Our study had a number of strengths, including its novel focus on frailty indicators and employment outcomes, its large sample size and its geographically dispersed population-based sampling strategy. Almost everyone in Britain registers with a general practice for healthcare that is free at the point of delivery, so patient lists from general practices offer a comprehensive sampling frame. The sampling frame also allowed us to calculate PAFs, providing an estimate of the potentially avoidable burden of work incapacity and loss as judged from a population perspective.

A limitation was the relatively low response rate at baseline. The prevalence of frailty could have been underestimated if those with more Fried symptoms were less likely to return a questionnaire. A differential response of that sort would not of itself bias associations between Fried symptoms and employment outcomes, which would be unrepresentative only if the association with employment differed between responders and non-responders. If frail non-responders were more handicapped than frail responders, this might lead to an underestimation of frailty's impact on employment. Conversely, 
Table 4 Associations between number of frailty symptoms and employment outcomes and perceptions by social class

\begin{tabular}{|c|c|c|c|c|}
\hline \multirow[b]{2}{*}{ Outcomes } & \multicolumn{3}{|c|}{ Frail vs not ( $\geq 3$ vs 0 symptoms) } & \multirow[b]{2}{*}{$\begin{array}{l}p \text { Value for } \\
\text { interaction }\end{array}$} \\
\hline & $\begin{array}{l}\text { Higher managerial } \\
\text { OR }(95 \% \mathrm{Cl})\end{array}$ & $\begin{array}{l}\text { Intermediate occupations } \\
\text { OR }(95 \% \mathrm{Cl})\end{array}$ & $\begin{array}{l}\text { Routine and manual occupations } \\
\text { OR }(95 \% \mathrm{Cl})\end{array}$ & \\
\hline \multicolumn{5}{|l|}{ Entire sample $(\mathrm{n}=8095)$} \\
\hline Not in work vs in work & 7.8 (4.3 to 14.2$)$ & 5.2 (3.0 to 9.0$)$ & $15.9(10.2$ to 24.8$)$ & $<0.001$ \\
\hline \multicolumn{5}{|l|}{ Those in work (maximum $\mathrm{n}=5486$ ) } \\
\hline \multicolumn{5}{|l|}{ Sick leave, days past 12 months: } \\
\hline Any vs none & $2.3(0.9$ to 5.8$)$ & $2.9(1.2$ to 6.7$)$ & $5.1(2.2$ to 12.0$)$ & 0.52 \\
\hline$>20$ days vs $\leq 20$ days & $13.3(5.1$ to 34.8$)$ & 5.1 (2.0 to 13.3$)$ & $15.6(7.1$ to 34.1$)$ & 0.44 \\
\hline \multicolumn{5}{|l|}{ Cut down on work, past 12 months: } \\
\hline Any vs none & $12.2(4.4$ to 33.9$)$ & $6.0(2.7$ to 13.4$)$ & 14.4 (5.8 to 35.7$)$ & 0.48 \\
\hline A lot vs not a lot (none/a little) & 21.7 (8.4 to 56.2$)$ & $13.2(5.5$ to 31.6$)$ & 23.1 (10.1 to 52.7$)$ & 0.92 \\
\hline \multicolumn{5}{|c|}{ Coping with work's physical demands (vs easily): } \\
\hline With some/great difficulty & $17.8(5.8$ to 54.6$)$ & 7.8 (3.3 to 18.4$)$ & $31.9(7.5$ to 134.6$)$ & 0.07 \\
\hline \multicolumn{5}{|c|}{ Coping with work's mental demands (vs easily): } \\
\hline With some/great difficulty & $3.5(1.4$ to 8.9$)$ & $2.7(1.2$ to 6.1$)$ & 10.1 (4.4 to 23.0$)$ & 0.01 \\
\hline \multicolumn{5}{|c|}{ Expecting to be able to cope in 2 years' time (vs yes): } \\
\hline No/not sure & 10.9 (3.8 to 31.2$)$ & 9.9 (4.2 to 23.6$)$ & 30.1 (9.0 to 100.2$)$ & 0.38 \\
\hline \multicolumn{5}{|c|}{ Lying awake at night worrying about work (vs sometimes/rarely/never): } \\
\hline Often & $6.7(2.7$ to 16.7$)$ & 4.1 (1.7 to 10.2$)$ & $8.9(4.1$ to 19.7$)$ & 0.24 \\
\hline \multicolumn{5}{|l|}{ Job security (vs secure/very secure): } \\
\hline Insecure/very insecure & $3.3(1.3$ to 8.4$)$ & $2.9(1.3$ to 6.6$)$ & $3.3(1.6$ to 7.2$)$ & 0.90 \\
\hline
\end{tabular}

Table 5 Associations of individual symptoms of frailty with employment outcomes and perceptions

\begin{tabular}{|c|c|c|c|c|c|}
\hline \multirow[b]{2}{*}{ Outcomes } & \multicolumn{5}{|l|}{ Risk factors } \\
\hline & $\begin{array}{l}\text { Weight loss } \\
\text { OR }(95 \% \mathrm{Cl})\end{array}$ & $\begin{array}{l}\text { Exhaustion } \\
\text { OR }(95 \% \mathrm{Cl})\end{array}$ & $\begin{array}{l}\text { Weak grip } \\
\text { OR (95\% Cl) }\end{array}$ & $\begin{array}{l}\text { Slow walking speed } \\
\text { OR }(95 \% \mathrm{Cl})\end{array}$ & $\begin{array}{l}\text { Low activity } \\
\text { OR ( } 95 \% \mathrm{Cl})\end{array}$ \\
\hline \multicolumn{6}{|l|}{ Entire sample $(\mathrm{n}=8095)$} \\
\hline Not in work vs in work & $1.6(1.3$ to 1.9$)$ & $3.8(3.1$ to 4.6$)$ & $2.4(2.1$ to 2.8$)$ & $6.8(5.4$ to 8.4$)$ & $1.4(1.3$ to 1.7$)$ \\
\hline Left for a health reason vs not & $2.6(2.1$ to 3.2$)$ & 7.9 (6.4 to 9.6$)$ & $6.6(5.5$ to 7.8$)$ & $14.8(12.2$ to 18.0$)$ & $2.6(2.2$ to 3.1$)$ \\
\hline \multicolumn{6}{|l|}{ Those in work (maximum $\mathrm{n}=5486$ ) } \\
\hline \multicolumn{6}{|l|}{ Sick leave, days in past 12 months: } \\
\hline Any vs none & 1.5 (1.2 to 1.8$)$ & 2.9 (2.2 to 3.8$)$ & $1.8(1.5$ to 2.2$)$ & $3.1(2.2$ to 4.4$)$ & $1.2(1.0$ to 1.4$)$ \\
\hline$>20$ days vs $\leq 20$ days & $3.5(2.7$ to 4.6$)$ & $3.9(2.8$ to 5.5$)$ & 2.7 (2.0 to 3.6$)$ & 5.1 (3.5 to 7.5$)$ & $1.7(1.3$ to 2.3$)$ \\
\hline \multicolumn{6}{|l|}{ Cut down on work, past 12 months: } \\
\hline Any vs none & $1.9(1.6$ to 2.3$)$ & 3.7 (2.9 to 4.8$)$ & 3.7 (3.1 to 4.6$)$ & $6.9(4.8$ to 9.7$)$ & $1.2(1.0$ to 1.5$)$ \\
\hline A lot vs not a lot (none/a little) & 2.6 (1.9 to 3.6$)$ & $5.5(4.0$ to 7.7$)$ & $4.4(3.3$ to 5.9$)$ & $9.6(6.7$ to 13.7$)$ & $1.4(1.1$ to 1.9$)$ \\
\hline \multicolumn{6}{|c|}{ Coping with work's physical demands (vs easily): } \\
\hline With some/great difficulty & 1.8 (1.5 to 2.2$)$ & 4.2 (3.3 to 5.5$)$ & 5.6 (4.5 to 6.8$)$ & $10.6(7.1$ to 15.9$)$ & $1.5(1.3$ to 1.7$)$ \\
\hline \multicolumn{6}{|c|}{ Coping with work's mental demands (vs easily): } \\
\hline With some/great difficulty & $1.4(1.2$ to 1.8$)$ & $3.8(2.9$ to 4.9$)$ & $2.4(2.0$ to 3.0$)$ & 1.9 (1.3 to 2.6$)$ & $1.3(1.1$ to 1.5$)$ \\
\hline \multicolumn{6}{|c|}{ Expecting to be able to cope in 2 years' time (vs yes): } \\
\hline No/not sure & $1.7(1.4$ to 2.1$)$ & $3.6(2.8$ to 4.7$)$ & 4.0 (3.2 to 4.8$)$ & $7.4(5.2$ to 10.5$)$ & $1.5(1.2$ to 1.7$)$ \\
\hline \multicolumn{6}{|c|}{ Lying awake at night worrying about work (vs sometimes/rarely/never): } \\
\hline Often & $1.6(1.2$ to 2.0$)$ & 5.0 (3.8 to 6.5$)$ & 1.9 (1.5 to 2.4$)$ & $2.4(1.7$ to 3.5$)$ & $1.4(1.1$ to 1.7$)$ \\
\hline \multicolumn{6}{|l|}{ Job security (vs secure/very secure): } \\
\hline Insecure/very insecure & $1.3(1.0$ to 1.6$)$ & $1.8(1.4$ to 2.5$)$ & $1.6(1.3$ to 2.0$)$ & $2.1(1.5$ to 2.9$)$ & $1.0(0.8$ to 1.2$)$ \\
\hline
\end{tabular}

overestimation could arise if frail individuals with greater work handicap participated more readily in the survey; but bias of this second kind seems less likely as the items we used to assess frailty formed only a small part of a much larger question set and were dispersed through the questionnaire, helping to disguise this focus of interest from participants. Nonetheless, it will be important to confirm findings longitudinally in a cohort with good follow-up rates. (The HEAF Study is well placed in this respect, as response rates at follow-up have exceeded $80 \%)$. 
A second limitation is that we had no face-to-face contact with subjects and so were unable to perform a physical examination or conduct tests of performance. Fried's criteria are usually based on answers to two questions (reproduced in our questionnaire) in combination with measures from tests of physical performance performed according to standardised protocols. In this large cross-sectional study across England, we depended on questions about symptoms to gauge functional elements (eg, grip strength) that we were unable to measure directly. We do not know how accurately our proxy questions reflected what would have been found had objective measurements been available. However, as yet there is no international consensus on how best to assess frailty in older people for research purposes, ${ }^{13}$ the Fried Scale has been adapted successfully in other research using proxy information when components could not be ascertained in the manner originally specified. ${ }^{11} 16{ }^{17}$ Moreover, data from another cohort study of older workers, the 10-country Survey of Health, Ageing and Retirement in Europe (SHARE), which did include objective measures of physical function, estimated a broadly similar prevalence of 'frailty' and 'prefrailty' among people of similar age to those in our study. ${ }^{11}$ Even if the ascertainment of Fried components was accurate, the phenotype that they represent in late middle age may not be the same as in the elderly. Nevertheless, they showed consistent and strong associations with poor employment outcomes in our study sample.

Those classified as 'frail' by our study were about five times more likely to report low well-being and persistent pain, which like frailty were possible risk factors for HRJL, sickness absence and reduced work capacity. Adjustment for these potential confounders somewhat reduced associations between frailty and adverse work outcomes, although they remained robust and strong.

We know of no other study that has explored frailty's relations to work. However, the Work-Ability Index (WAI) is another measure that has been linked with poor employment outcomes as well as predicting poorer long-term health. ${ }^{18}$ It assesses seven domains, all self-reported: current work capacity relative to lifetime best; work ability in relation to the physical and mental demands of the job; work impairment because of health; amount of sick leave in the past 12 months; expectations about work ability in 2 years' time; number of current physician-diagnosed diseases and 'mental resources' (enjoyment, energy and hope for the future). It may be seen that none of these matches the Fried frailty criteria, although the domain of 'mental resources' partially overlaps Fried's criterion for exhaustion. An important point of contrast between the two scales is that most of the WAI's domains are intended for application only in those in work, whereas the Fried criteria can be used without such restriction; this in turn enabled us to treat several elements of WAI (work ability in relation to the physical and mental demands of the job, sick leave, impaired work productivity, expectations of future working) as adverse work outcomes (tables 3-5), rather than as predictors of adverse work outcomes. The Fried criteria therefore offer a flexible alternative to WAI, capable of use against a number of additional economically important end points.

Associations between frailty and poor work outcomes appeared to be driven principally by slow walking speed, weak grip strength and exhaustion, suggesting that poor motor function could be an important underlying factor (as perhaps it may be for some people with a poor WAI Score); and if so, that future interventions might focus on improving motor function. It might be supposed that heavy manual work would help to build and preserve physical strength, but paradoxically, for measured hand grip strength, there is evidence to the contrary, ${ }^{19} 20$ perhaps reflecting social inequalities in health that outweigh any advantages of physical effort at work. ${ }^{20}$ In the current analysis, associations with not being in work, taking sick leave and not coping were strongest in manual/routine occupations. This differential could arise because of their generally poorer physical health or, more simply, a greater mismatch between physical capability and job demands-the ability of manual workers to carry out their jobs being more likely to be compromised by a given impairment of physical function.

Since our analysis was cross-sectional, interpretation of the associations is necessarily limited, particularly as all of the data were self-reported. However, the HEAF Study includes a prospective component, and it has the capacity to link questionnaire responses with personal primary care medical records providing details of medical diagnoses, hospital care and prescribed treatments. In future, therefore, we plan to assess longitudinal relationships between frailty elements in middle life and medically recorded health and health change, and between frailty and changes in employment status. We hope also to assess physical function in face-to-face interviews. Opportunity exists, therefore, to characterise people with multiple Fried symptoms in our study in greater clinical detail and to follow their progress over time.

A future goal may be to develop simple screening tests to identify components of physical frailty in older workers and then to devise interventions that could improve their physical function. A screening tool becomes particularly attractive if it is positive in only a small proportion of the population but accounts for a substantial proportion of that population's adverse outcomes: in this respect, the findings reported here (the low prevalence of $\geq 3$ frailty symptoms but their high associated PAF) encourage us to explore this issue further in future research, especially as interventions to combat frailty in the elderly have enjoyed some success. ${ }^{8-10}$

\section{Author affiliations}

${ }^{1}$ MRC Lifecourse Epidemiology Unit, University of Southampton, Southampton, UK ${ }^{2}$ Arthritis Research UK/MRC Centre for Musculoskeletal Health and Work, University of Southampton, Southampton, UK

${ }^{3}$ Centre for Cognitive Ageing and Cognitive Epidemiology, Department of

Psychology, University of Edinburgh, Edinburgh, UK

${ }^{4}$ Centre for Research on Ageing, University of Southampton, Southampton, UK

${ }^{5}$ Farr Institute, University of Manchester, Manchester, UK

${ }^{6}$ Utrecht Institute for Pharmaceutical Sciences, Utrecht University, Utrecht, The Netherlands

${ }^{7}$ NIHR Collaboration for Leadership in Applied Health Research and Care Wessex, University of Southampton, Southampton, UK

${ }^{8}$ Institute of Neuroscience, Newcastle University, Newcastle, UK

${ }^{9} \mathrm{NIHR}$ Newcastle Biomedical Research Centre, Newcastle University, Newcastle, UK

${ }^{10}$ Newcastle upon Tyne Hospitals NHS Foundation Trust, Newcastle, UK

Acknowledgements We wish to thank the CPRD and the 24 general practices that have supported data collection; also, the staff of the MRC LEU who provided invaluable support with data entry and computing, especially Helena Demetriou and Vanessa Cox.

Contributors KTP identified the study questions and, with DC, designed the study and its measuring instruments. KTP supervised data collection and, with SD, DC and $H S$, planned the analyses. SD conducted the analyses. KTP wrote the first draft of the paper. KW-B, SD, ECH, CL, AAS, CRG, ME, HS, TVS and CC contributed to the study's design, content, measuring instruments and plan of execution. Additionally, $\mathrm{ECH}$ and $\mathrm{CL}$ led in data collection, cleaning and preparation and the enlistment of participating general practices. All authors read and approved the final manuscript.

Funding This work was supported by Arthritis Research UK (grant numbers ARC 19817, ARUK 20665); the Medical Research Council and the Economic and Social Research Council jointly (grant number ES/L002663/1); and a Medical Research Council programme grant (number MRC_MC_UP_A620_1018). 
Competing interests $\mathrm{CC}$ has received consultancy fees and honoraria from Alliance for Better Bone Health, Amgen, Eli Lilly, GSK, Medtronic, Merck, Novartis, Pfizer, Roche, Servier, Takeda and UCB.

Patient consent Obtained.

Ethics approval NHS Research Ethics Committee North West-Liverpool East.

Provenance and peer review Not commissioned; externally peer reviewed.

Data sharing statement Requests for data sharing should be addressed to the corresponding author.

\section{REFERENCES}

1 Department for Work and Pensions. Fuller working lives: a framework for action. DWP, June 2014, ISBN 978-1-78425-184-0. https://www.gov.uk/government/ publications/fuller-working-lives-a-framework-for-action

2 Fried LP, Tangen CM, Walston J, et al., Cardiovascular Health Study Collaborative Research Group. Frailty in older adults: evidence for a phenotype. J Gerontol A Biol Sci Med Sci 2001;56:M146-56.

3 Clegg A, Young J, Illiffe S, et al. Frailty in elderly people. Lancet 2013;381:752-62.

4 Rockwood K, Howlett SE, MacKnight C, et al. Prevalence, attributes, and outcomes of fitness and frailty in community-dwelling older adults: report from the Canadian study of health and aging. J Gerontol A Biol Sci Med Sci 2004;59:1310-7.

5 Bandeen-Roche K, Xue QL, Ferrucci L, et al. Phenotype of frailty: characterization in the women's health and aging studies. J Gerontol A Biol Sci Med Sci 2006:61:262-6.

6 Ensrud KE, Ewing SK, Taylor BC, et al. Comparison of 2 frailty indexes for prediction of falls, disability, fractures, and death in older women. Arch Intern Med 2008;168:382-9.

7 Boyd CM, Ricks M, Fried LP, et al. Functional decline and recovery of activities of daily living in hospitalized disabled older women; the Women's Health and Aging Study 1. J Am Geriatr Soc 2009;57:1757-66.

8 Cooper C, Dere W, Evans W, et al. Frailty and sarcopenia: definitions and outcome parameters. Osteoporos Int 2012;23:1839-48.
9 Faber MJ, Bosscher RJ, Chin A Paw M, et al. Effects of exercise programs on falls and mobility in frail and pre-frail older adults: a multicentre randomized controlled trial. Arch Phys Med Rehabil 2006;87:885-96.

10 Peterson MJ, Sloane R, Cohen $\mathrm{HJ}$, et al. Effect of telephone exercise counselling on frailty in older veterans: project LIFE. Am J Mens Health 2007:1:326-34.

11 Santos-Eggimann B, Cuenoud P, Spagnoli J, et al. Prevalence of frailty in middle-aged and older community-dwelling Europeans living in 10 countries. J Gerentol A Biol Sci Med Sci 2009;64A:675-81.

12 Palmer KT, Walker-Bone K, Harris EC, et al. Health and Employment after Fifty (HEAF): a new prospective cohort study. BMC Public Health 2015;15:1071.

13 Bouillon K, Kivimaki M, Hamer M, et al. Measures of frailty in population-based studies: an overview. BMC Geriatr 2013:13:64.

14 Office for National Statistics. Standard occupational classification. 2010 (SOC2010). http://www.ons.gov.uk/ons/guide-method/classifications/ current-standard-classifications/soc2010/index.html (accessed 10 Aug 16).

15 Stewart-Brown S, Janmohamed K. Warwick-Edinburgh Mental Well-being Scale. User Guide, v1 (June 2008). http://www.healthscotland.com/uploads/documents/ 7551-WEMWBS\%20User\%20Guide\%20Version\%201\%20June\%202008.pdf (accessed 10 Aug 16)

16 Kalousova L, Mendes de Leon CM. Increase in frailty of older workers and retirees predicted by negative psychosocial working conditions on the job. Soc Sci Med 2015;124:275-83.

17 Syddall HE, Westbury LD, Cooper C, et al. Self-reported walking speed: a useful marker of physical performance among community-dwelling older people? J Am Med Dir Assoc 2015:16:323-8.

18 Tuomi K, Ilmarinen J, Jahkola A, et al. Work Ability Index. 2nd edition. Helsinki: Finnish Institute of Occupational Health, 1998. ISBN 951-802-202-X.

19 Russo A, Onder G, Cesari M, et al. Lifetime occupation and physical function: a prospective cohort study on persons aged 80 years and older living in a community. Occup Environ Med 2006;63:438-42.

20 Walker-Bone K, D'Angelo S, Syddall HE, et al. Heavy manual work throughout the working lifetime and muscle strength among men at retirement age. Occup Environ Med 2016;73:284-6. 